\title{
Research on the Establishment and Stability of the Beijing-Tianjin-Hebei Region Air Pollution Cooperative Control Alliance: An Evolutionary Game Approach
}

\author{
Wei. Zhu ${ }^{1}$, ${ }^{1}$ Shaonan. Shan ${ }^{1 D},{ }^{1,2}$ Xiaohui. Shi ${ }^{D},{ }^{1,3}$ and Hui. Li ${ }^{4}{ }^{4}$ \\ ${ }^{1}$ School of Urban Economics and Public Administration, Capital University of Economics and Business, Beijing 100070, China \\ ${ }^{2}$ School of Business Management, Liaoning Vocation Technical College of Modern Service, Shenyang 110164, Liaoning, China \\ ${ }^{3}$ School of Economics and Management, Shanxi Normal University, Linfen 041004, China \\ ${ }^{4}$ School of Management, Guangxi University for Nationalities, Nanning, Guangxi 530006, China
}

Correspondence should be addressed to Shaonan. Shan; rose_1844100@cueb.edu.cn

Received 15 April 2021; Accepted 24 August 2021; Published 3 September 2021

Academic Editor: Fang Zhang

Copyright (c) 2021 Wei. Zhu et al. This is an open access article distributed under the Creative Commons Attribution License, which permits unrestricted use, distribution, and reproduction in any medium, provided the original work is properly cited.

\begin{abstract}
Air pollution control refers to a vital issue in the integrated and coordinated development of the Beijing-Tianjin-Hebei region. As impacted by the fluidity of air pollution, air pollution control cannot be achieved independently by a single local government in the Beijing-Tianjin-Hebei region, and a long-term mechanism should be established for regional coordination and cooperative control. However, in the pursuit of maximising benefits by the participating parties, difficulties in effective coordination between the various control bodies occurred and a dilemma was created in the cooperative control of air pollution in the Beijing-TianjinHebei region. Based on the existing research, this study first builds an evolutionary game model to analyse the evolutionary path and stability of cooperative alliance of air pollution control behaviour in the Beijing-Tianjin-Hebei region. Second, this study explores the core elements of reaching alliances and consolidating cooperative control among cities in the Beijing-Tianjin-Hebei region. Last, in combination with the simulation results, this study compares the feasibility of cooperative control among cities in the Beijing-Tianjin-Hebei region with and without central government constraints. As indicated from the results, without the constraints of the central government, intergovernmental cooperative control is correlated with intercity public benefits, cities' own benefits, and air pollution losses, whereas it is not effective since it cannot control the phenomenon of "free-riding" by cities in the Beijing-Tianjin-Hebei region. Under the control of the central government, a stable strategy among cities can evolve toward a fast and efficient cooperative management. To achieve air pollution control effectively, the air pollution control alliance should be formed in the Beijing-Tianjin-Hebei region, and the benefits of cooperation lay the basis for reaching cooperative control. The mentioned findings highlight that (1) the benefits of cooperation lay the basis for cooperative control, (2) punitive policies of central government increase the evolutionary rate of cooperative control, and (3) cooperation costs determine the long-term stability of the alliance.
\end{abstract}

\section{Introduction}

Industrialization and urbanization comply with fossil as the main energy source. In such a process, air pollution gradually becomes a vital factor of human health, ecological and environmental quality, as well as economic development. The prevention and control of air pollution is arduous, complicated and long-term, which is one of the topics of common concern for all nations worldwide. In 2019, the Global Environment Outlook 6 issued by the United Nations
Environment Programme highlighted that air pollution is the major environmental factor leading to the global burden of disease, thereby causing 6 to 7 million premature deaths each year. Air pollution threatens human health, while adversely affecting the economy. It is estimated that air pollution causes over $\$ 2.9$ trillion (taking up 3.3\% of global GDP) in global economic losses each year, which is attributed to fossil fuel emissions alone [1]. In the historical process of human development, numerous developed nations and regions have experienced large-scale outbreaks of 
air pollution, all of which have had extremely adverse effects. According to Table 1, in the process of control, nations have adopted different measures. To be specific, some have focused on environmental legislation, some have used a combination of administrative and economic measures, some have stressed the collaboration of relevant factors, and some have focused on the role of information disclosure in improving air quality [2-6]. In brief, air pollution control measures vary from country to country, and the mentioned measures have improved air quality.

Over the past few years, China's air pollution problem has become increasingly prominent. The "Global Air Quality Report 2020" released by IQ Air disclosed that China ranked in the middle of the world's nations/regions for the annual average concentration of PM2.5 $\left(\mu \mathrm{g} / \mathrm{m}^{3}\right)$ and population weight. Moreover, Beijing also ranks 14th in the world's capital city rankings. Air pollution has become one of the top issues that should be urgently solved by China. The BeijingTianjin-Hebei region is one of the most densely distributed and economically powerful regions in China. During the rapid industrialization and urbanization, the continuous growth of resource and energy consumption has imposed much pressure on the atmospheric environment [7]. As impacted by the dual effect of atmospheric circulation and atmospheric chemistry, air pollution in neighbouring cities affects each other. As suggested from the Communique on China's ecological environment in 2019 issued by the Ministry of Ecological and Environment of the People's Republic of China, no city in the Beijing-Tianjin-Hebei region ranked among the top 20 cities with relatively good air quality. Besides, among the 20 with relatively poor air quality, 15 cities were located in the Beijing-Tianjin-Hebei region. Furthermore, according to the National Urban Air Quality Report issued by the Ministry of Ecology and Environment of the People's Republic of China, this problem has been highlighted by the air quality in the three major regions monitored by China from March 2020 to February 2021 (Figure 1, for details). As indicated from the data, the proportion of days with good air quality in cities in the Beijing-Tianjin-Hebei region is significantly lower than that of cities of the other two regions. The Beijing-Tianjin-Hebei region is critical in winning the battle against the blue sky.

Moreover, the Beijing-Tianjin-Hebei region is also the first region to carry out cooperative air pollution control. Since 2013, as guided by a series of central policies (central policies include the Guiding Opinions on Promoting Joint Prevention and Control of Air Pollution to Improve Regional Air Quality, The 12th Five-Year Plan for Prevention and Control of Air Pollution in Key Regions, Air Pollution Prevention and Control Action Plan, etc.), the BeijingTianjin-Hebei region has been exploring the path of cooperative air pollution control. (1) For policies, according to the Beijing-Tianjin-Hebei 13th Five-Year Plan for Environmental Protection and Ecological Construction and the Beijing-Tianjin-Hebei Synergistic Development Ecological and Environmental Protection Plan, the control ranges of $\mathrm{NO}_{X}$ emissions and PM2.5 concentration were, respectively, proposed. (2) In 2017, the former Ministry of Environmental Protection issued the 2017 Air Pollution Prevention and
Control Work Plan for Beijing-Tianjin-Hebei region, which listed 28 cities in the Beijing-Tianjin-Hebei region as the Beijing-Tianjin-Hebei air pollution transmission channel cities. (3) In 2018, the Beijing-Tianjin-Hebei region's 2018-2019 Autumn and Winter Comprehensive Air Pollution Control Action Plan was issued to strengthen the emergency response to serious pollution weather. (4) The 2019 Beijing-Tianjin-Hebei region's Action Plan for Comprehensive Control of Air Pollution in the Autumn and Winter of 2019-2020 requires deepening regional emergency response and strengthening joint law enforcement. (5) The 2021 Government Work Report further highlighted that this year, we will "strengthen the comprehensive efforts and joint prevention and control of air pollution, and boost the coordinated control of fine particulate matter and ozone." In such a scenario, an in-depth research on air pollution control in the Beijing-Tianjin-Hebei region should be urgently conducted.

In special periods, China has also taken some special joint measures to prevent and control air pollution. In 2014, during the APEC summit in Beijing, the Beijing-Tianjin-Hebei region has taken the concerted measures to reduce emissions (e.g., the closure of coal-fired boilers, the shutdown of industrial enterprises, the suspension of dusty construction sites, and the restriction and control of motor vehicles). These measures have improved air quality, and the "APEC Blue" has emerged. In 2015, Beijing actively coordinated the joint emission reduction of neighbouring provinces and cities, thereby significantly improving the quality of the urban air, and the "Parade blue" appeared. "APEC Blue" and "Parade Blue" proved intergovernmental cooperation as an effective measure for regional environmental control. Obviously, neither the "APEC Blue" nor the "Military Parade Blue" have been stably maintained. Accordingly, the particularity of air pollution and the long-term mechanism of intergovernmental cooperation should be studied to control the pollution. The atmosphere is typical public goods, and atmospheric pollutants can easily spread to the surrounding areas, so it is easy to cause "tragedy of the commons" and "free-riding" during pollution control. The problem is that the pollution control process is prone to "tragedy of the commons" and "freerider". Thus, air pollution is not a problem of one city in a region and should break the model of territorial autonomy [8]. Experience has revealed that once the central government's intervention force disappears, local governments will fall into a state of separate control again. For this reason, it is necessary to coordinate deployment at the national level, design reward, and punishment mechanisms, and promote intergovernmental collaboration. Since the end of the 20th century, the intergovernmental cooperation model of environmental control has always been a vital issue in environmental protection research. Many nations and regions come to realize that forming a regional control alliance can most effectively abate air pollution. Given this, cooperative control of air pollution is a hopeful and urgent issue.

In brief, according to the research overview of cooperative control of air pollution, though researchers have made significant progress in this field, the following problems and challenges remain: 
TABLE 1: Air pollution control measures in the US, UK, Italy, Japan, and Germany.

Air pollution events

Photochemical pollution incident in Los Angeles, USA

Smog type air pollution incident in London, UK

Air pollution incident in Milan, Italy

Asthma incident in Yokkaichi, Japan

Events in the Ruhr, Germany

Control measures

The Los Angeles government set the South Coast Air Quality Management District to manage emissions. The Los Angeles government has adopted five measures, i.e., government-led, market-regulated, legal, public-driven, and technology-supported

London has adopted four measures, i.e., legislation to improve monitoring standards, strengthening motor vehicle management in vital areas, vigorously developing public transportation and bicycle transportation, and scientifically building urban green belts

The government of Milan primarily launches air pollution prevention and control by adopting some specific administrative measures, including the establishment of additional traffic control zones in the centre of the city, the imposition of traffic congestion charges and vehicle emission

fees, the implementation of centralized heating, "car ban", and many other measures

Japan has promulgated a series of laws regarding environmental protection, compiled environmental protection teaching materials, and opened environmental education courses in various schools to progressively increase public awareness to help address environmental issues.

There were also other measures (e.g., the socialization of waste disposal and the internationalization of data information) taken

German environmental policy tools largely cover environmental education, laws, subsidies, environmental taxes, investment subsidies, and environmental audits. Germany's policies are diversified, set strict environmental quality standards, and support technological innovation

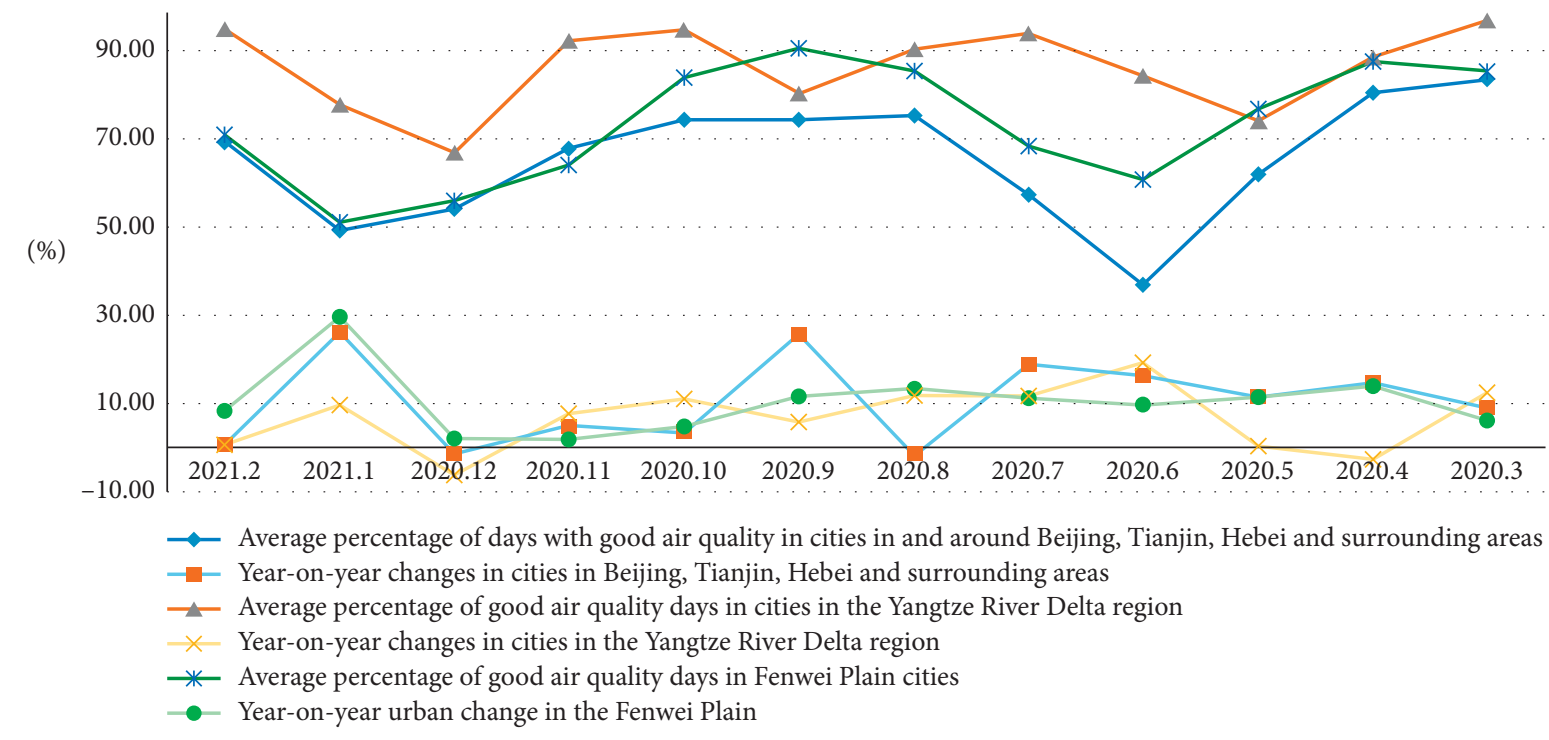

FIGURE 1: Air quality conditions in three key regional cities.

(1) Whether they can form a strategic alliance spontaneously without government control?

(2) Under the reward and punishment measures of the central government, whether the alliance can be achieved? How about the stability of the alliance?

(3) How to design the control measures of the central government to develop a long-term effective cooperative control alliance?

Based on the mentioned problems, this study uses evolutionary game theory to construct a decision-making framework for cooperative intergovernmental air pollution control, as shown in Figure 2.

The rest of this study is organized below. In Section 2, the relevant literature studies on air pollution control, local government cooperative control, and involvement of game theory in environmental pollution problems are comprehensively reviewed. In Section 3, the research questions are defined, and a decision framework for cooperative intergovernmental air pollution control behaviour is designed. In Section 4, the evolutionary game model of two intergovernmental air pollution cooperative control alliances is established. In Section 5, the gradual stability and evolutionary stability strategies of the equilibrium point are analysed. In Section 6, the factors of the long-term mechanism of intergovernmental collaboration in air pollution control are explored. In Section 7, the research of this study is summarized, and the defects and future directions of the research on this issue are presented.

\section{Literature Review}

Over the past few years, intergovernmental cooperation in air pollution control has received increasing attention. The relevant literature studies mainly focused on the following 


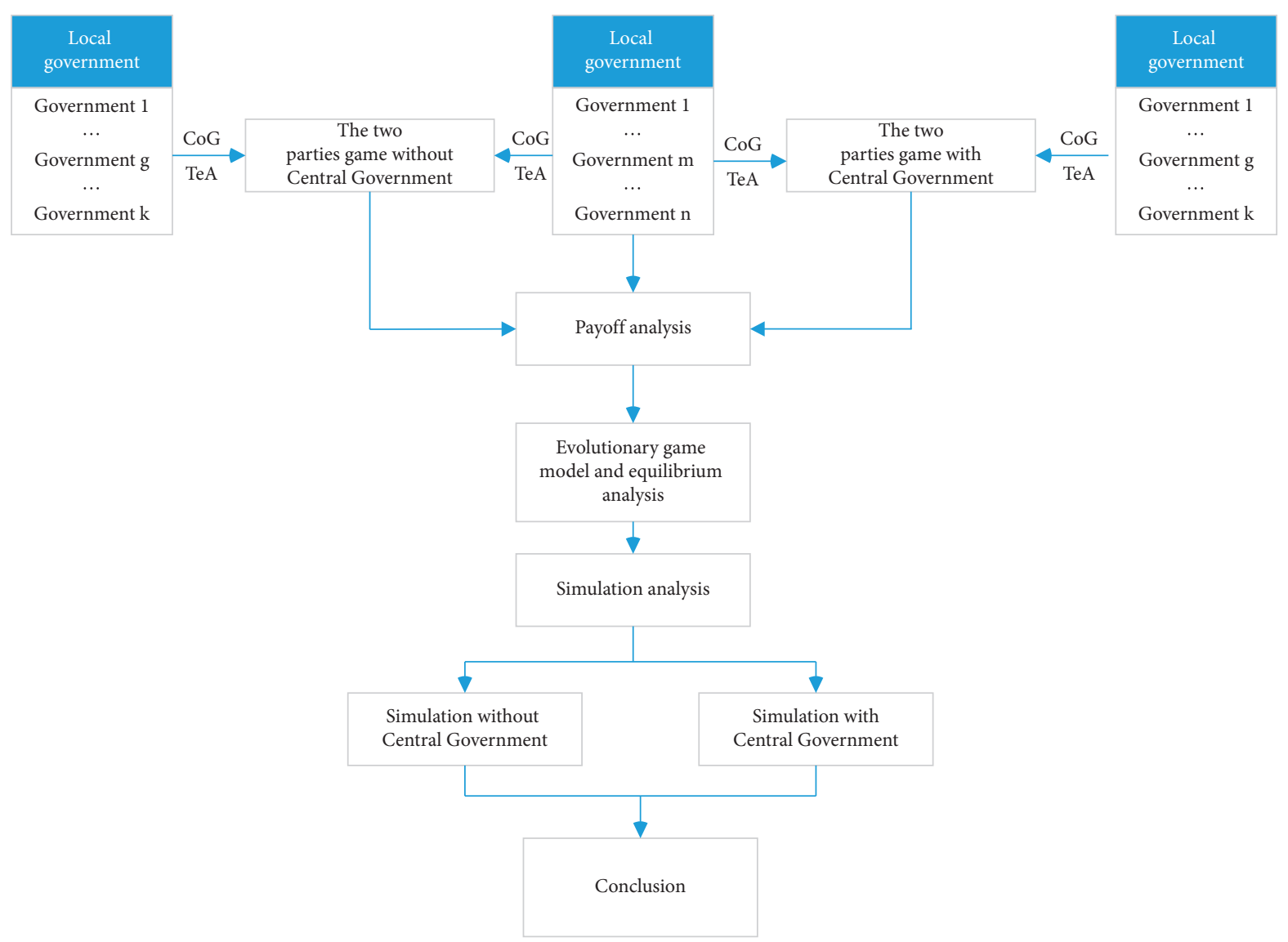

FIgURE 2: The whole process of modelling and simulation involved in this study.

aspects: (1) air pollution prevention and control, (2) preferences of local governments for cooperative control, and (3) involvement of game theory approach to analyse environmental pollution.

2.1. Air Pollution Prevention and Control. The existing research on air pollution prevention and control largely focused on two aspects: air pollution control system and quantitative analysis of air pollution control.

Over the past few years, the government and scholars have continued to focus on the system of air pollution control policies. The Ministry of Environmental Protection of the People's Republic of China issued the Air Pollution Prevention and Control Action Plan on September 27, 2012. In 2013, China issued the Action Plan for Air Pollution Prevention and Control, which launched an air pollution prevention and control program for the period of 2017-2020. The implementation of such a program can effectively reduce PM2.5 pollution levels in the BeijingTianjin-Hebei region. There are also a series of policies released over the past few years, as mentioned above, which regulate the cooperative control of air pollution in the Beijing-Tianjin-Hebei region [9]. However, the implementation of the mentioned plans and regulations has encountered considerable difficulties since policymakers have mainly adopted a "command and control" approach to promote cooperation without adequately and scientifically considering the economic incentives for participants $[10,11]$. The prevention and control of air pollution require the strict environmental laws and regulations of the central government, as well as the enforcement of clear rewards and penalties. When there are obstacles for local governments to control air pollution, the central government is required to supervise the implementation of prevention and control policies. $\mathrm{Li}$ [12] discussed the improvement of pollution control policies and considered that the corresponding pollution emission trading mechanism should be established in the United States. Moreover, the central government should supervise the implementation of the mentioned policies. Gormley (1987) discussed how to determine the air quality control standards and assign enforcement powers between the central and local governments. He considered that the key lies in whether clean air should prioritize cost [13].

Some literature studies quantitatively analysed air pollution control. Zheng and Luo [14] used a DEA model to measure panel data on air pollution control in 29 provinces and cities in China. They concluded that both regulatory and market-based policy instruments are effective in air pollution control in China. On that basis, Xue et al. [15] used a shapley game to study the effectiveness of the control of air sulphur dioxide pollution in the Beijing-Tianjin-Hebei region between 2003 and 2009 and found that local 
environmental protection agencies preferred joint control and were more cost-effective. To more effectively prove the mentioned point, the authors proposed a cooperative econometric model for the inter-regional air pollution control. Through a control experiment on air pollution control, Xiao et al. [16] found that in the process of local government cooperative control, a strong environmental regulation mechanism could effectively promote the improvement of local air quality. Xue [17] examined the effectiveness of regulatory tools and quantified the relationship between the National Total Emission Control (NTEC) and the national average concentrations of $\mathrm{SO}_{2}$ and $\mathrm{NO}_{2}$ in 2015.

In brief, though numerous scholars have conducted extensive studies on air pollution control and obtained some findings and meaningful conclusions, the current regional air pollution control effect remains poor. Besides, the existing literature has not explored in-depth the implementation strength of air pollution control subjects and the stability of the intersubject interaction game in joint control, and the mentioned gaps offer opportunities and insights for subsequent studies.

\subsection{Cooperation Preferences in Local Government Atmo-} spheric Control. Due to the compound and mobile nature of air pollution, a single territorial government cannot accomplish air pollution control alone. Increasingly local governments realize that the need to break the territorial jurisdictional restrictions and to reach a cooperative alliance is critical to the effective prevention of air pollution [18]. Some scholars have already started to explore the implementation possibilities of local government cooperation in air pollution control. For instance, Wei [19] proposed a multiterritory emergency "task-driven" cooperative control model based on the "structure-process-effect" chain, which can effectively control air pollution in a short period, whereas the cooperative control is unstable for the lack of legislation and information asymmetry. [20] Multiple barriers in technology, economy, and environment between different regions have caused local governments to be reluctant to cooperate, while the process of cooperation is full of obstacles.

Given this, some scholars have placed more stress on the research on the lasting stability of the cooperative control and transboundary control. John [21] et al. emphasized the importance of "starting conditions-process-structure and control-contingent events and factors-consequences and responsibilities" in inter-regional cooperation. Andreas [22] proposed multilevel social participation, public consultation, and other ways by conducting the normative analysis. Some studies considered the awareness of the atmospheric environment as a vital factor for the achievement and stability of cooperation. For instance, Min (2002) [23] noted in his study that as the level of environmental awareness increased, the number of participating regions and the benefits of cooperation would increase, so the stability and effectiveness of cooperation would be improved. Yu [24] analysed the relationship between air pollution and synoptic pattern during a severe haze episode in the Zhejiang province. The results suggested that the joint efforts with neighbouring provinces to mitigate pollutant emissions could be important to improve air quality in Zhejiang during winter. Besides, some scholars have explored the drivers of cooperation from the perspectives of dependency relationships and common interests among cooperative subjects [25-28].

In brief, existing studies have achieved some results regarding crossregional cooperative air pollution control, whereas there has been limited research on the stability of the interactive game among the subjects of cooperative air pollution intergovernmental control. To solve the mentioned problem, this study starts with the control body, discusses the factors of cooperative intergovernmental control, the interactive game behaviour of joint control among local governments, and the stability of the cooperative intergovernmental control.

\subsection{The Involvement of Game Theory in Environmental Pol-} lution Problems. Game theory acts as an effective theoretical approach to the analysis and solution of environmental pollution problems. In 1968, Hardin [29] published a paper on the tragedy of the Commons. He highlighted that if the public resources were overused without any restrictions, the public resources would be overall exhausted. As a result, the game theory approach has evolved in the study on environmental pollution problems [30-32], from the classical game theory approach under perfect rationality to the evolutionary game approach under finite rationality, from static games to dynamic games, as well as from information symmetric games to noninformation symmetric games [33]. Over the past few years, the evolutionary game theory has been extensively used in economics and management to study issues (e.g., territorial government behaviour strategy selection $[34,35]$, dynamic evolutionary trends $[35,36]$, and persistent cooperative coalition reaching [37-39]). In particular, the evolutionary game theory can capture the limited rationality among local governments. Accordingly, the evolutionary game theory is well suited to solve the intergovernmental cooperative control of air pollution.

For instance, Kucukmehmetoglu and Guldmann [40] used the cooperative game theory to explore the problem of river allocation control in three nations. Kennedy [41] analysed the noncooperative game behaviour of environmental control decisions in imperfectly competitive markets for the local governments. Petrosyan and Yeung [38] developed a novel class of cooperative dynamic games with multiple durable controls of different lag durations. Suzuki and Iwasa [42] refined the various factors of the lake pollution problem, regarded various psychological factors as a type of social pressure, and exploited the evolutionary game theory to analyse the cooperative behaviour of different interest groups. Yanase [43] compared emission taxes and command-andcontrol regulations. Moreover, they concluded that stricter emission policies can avoid the "free-rider" phenomenon and stimulate the company's competitiveness. On this basis, the game results reveal that the effect of emissions tax on pollution and social welfare is more significant. Furthermore, some scholars have also developed evolutionary game models and centralized-decentralized game theoretic models with 
functional departments, local governments, and end-users as the main players to analyse the effect of the government on corporate behaviour [44-47].

With the expansion of the application field of game theory, people have begun to question the assumption of complete rationality of the game players in the conventional game theory. Thus, some scholars proposed some new ideas (e.g., the cooperative evolution problem under imitation conditions [48] and the adaptive learning mechanism of individuals [49]). The mentioned literature studies enrich the evolutionary game theory system. Most of the time, the evolutionary game theory is more suitable than the classical game theory for analysing the relationship between multiple subjects in a coalition [50]. Most researchers focused on static games between two players under a single constraint, which addressed only the question of whether subjects in a coalition cooperate. However, in the actual case, the constraints are varying, and the stability of the subject's cooperation will change accordingly. In this context, this study investigates the evolutionary game process and its stability with and without central government constraints, respectively, to seek universal mechanisms affecting the effectiveness of local government air pollution control.

In brief, despite the growing interest in interprefectural cooperative air pollution control, it remains in its infancy. First, most of the existing research literature studies assumed that local governments participating in cooperative air pollution control coalitions are perfectly rational, i.e., they choose strategies to maximize their interests. However, the actual situation shows that local governments always behave with limited rationality, so further in-depth research should be conducted in this field. Second, most researchers only focused on how to establish cooperative air pollution control alliances, and the analysis of the stability of control alliances and the sustainability of environmental protection are insufficient. Last, according to the existing literature, researchers have mostly employed static games and two-bytwo evolutionary games between localities to complete the study on cooperative air pollution control. In addition, rare studies have incorporated central government control into the game process. Based on the mentioned research, this study proposes a decision framework for intergovernmental cooperative air pollution control, builds an evolutionary game model of the two under different constraints, and solves the model using optimal control theory. This study aims at verifying and solving the proposed model, as well as to highlight the importance and urgency of establishing cooperative air pollution control alliances among local governments. Table 2 lists some selected research works.

\section{A Comprehensive Decision-Making Framework for Cooperative Air Pollution Control}

3.1. Problem Definition. "Atmosphere" refers to typical public goods, and the flow of air pollution is transregional, so air pollution exhibits a significant negative externality. In this case, the marginal benefit obtained by a local government when it carries out air pollution control is smaller than the total marginal benefit to society. Thus, under the local government self-control model, local government investment in the environmental control will be insufficient. Moreover, under the pressure of economic assessment, between the regional GDP growth and air pollution prevention, local governments are inclined to neglect the control of air pollution and even sacrifice the air environment to develop the economy.

At present, under the serious pollution situation, the central government has repeatedly stressed air pollution control as the primary issue of national environmental controls. Under the policy requirements, cities in the Beijing-Tianjin-Hebei region have two options, i.e., (1) selfcontrol and (2) reaching a cooperative control alliance with other cities and combat air pollution together. They can fall to two groups, one for cities with a better economic base and the other for cities with a weaker economic base. In the former group of cities, the "free-rider" effect will discourage air pollution control, thereby causing insufficient investment. Cities in the latter group will also reduce their investment in air pollution control for their weaker economic base and the "free-rider" effect. Besides, intergovernmental cooperation has transaction costs, autonomous negotiations among local governments cannot easily form cooperative alliances, and different definitions of rights among governments can lead to different efficiencies of resource allocations. Thus, the control of air pollution is not a problem of one city in a region, and the territorial autonomy model cannot achieve satisfactory results, so the path that can better solve the problem of air pollution should be explored.

3.2. An Integrated Decision Framework. Considering the complexity of air pollution control and the need for each participating subject to find the best strategy through continuous learning, the imitation, trial error evolutionary game approach is a better choice. According to the above analysis, a two-player evolutionary game decision framework regarding intergovernmental cooperative control is constructed. This framework mainly analyses the selection strategy, the stability of the air pollution control alliance, the control effect, and the sustainable development issues. It is depicted in Figure 3.

In this study, the players in the evolutionary game model include the control alliance, the central government, and the relevant cities we studied above. They are all bounded rational. We will analyse the subjects from two models: one is a coordinated control of air pollution without the constraints of the central government, and the other is the coordinated control of air pollution under the constraints of the central government. In both models, relevant cities have the right to choose to join or not to join the control alliance. In the first model, we will analyse the possibility of forming a control alliance and the stability of the control alliance. In the second mode, we will continue to analyse the above issues. Through comparative analysis, the factors of intergovernmental cooperative control are clarified, the evolution direction of intergovernmental cooperative control is explored, and last a better path for air pollution control is found. 
TABLE 2: A brief summary of most relevant works.

\begin{tabular}{|c|c|c|c|c|}
\hline Ref. & Year. & Method. & Shortcoming. & Finding. \\
\hline Li et al. & {$[30]$} & $\begin{array}{l}\text { A CLSC model with a } \\
\text { manufacturer and a retailer, and } \\
\text { the market demand is determined } \\
\text { by the price, the carbon emission } \\
\text { reduction level as well as the low- } \\
\text { carbon promotion effort }\end{array}$ & $\begin{array}{l}\text { First, most of the existing research } \\
\text { literature assumes that local } \\
\text { governments participating in } \\
\text { cooperative air pollution control } \\
\text { coalitions are perfectly rational. } \\
\text { Second, the analysis of the stability } \\
\text { of control alliances and the } \\
\text { sustainability of environmental } \\
\text { protection is insufficient. Last, } \\
\text { fewer studies have incorporated } \\
\text { central government control into } \\
\text { the game process }\end{array}$ & $\begin{array}{l}\text { First, this study assumes that local } \\
\text { governments are finitely rational. } \\
\text { Second, they have built an alliance } \\
\text { of city clusters and hope to } \\
\text { promote this model. Last, they } \\
\text { constructed two models, one for } \\
\text { coalitions without central } \\
\text { government constraints and one } \\
\text { for coalitions with central } \\
\text { government constraints, and the } \\
\text { comparison of the two models can } \\
\text { illustrate the role of central } \\
\text { government in the control } \\
\text { process }\end{array}$ \\
\hline
\end{tabular}

The paper analysed a

transboundary pollution

De Frutos et al. [31] differential game where pollution

control is spatially distributed

among a number of agents with

predetermined spatial relationships

A dynamic game was used to study

Cabo et al.

[34] a transboundary pollution problem

between two neighbouring regions

The paper provided a survey of the

Jørgensen et al. [32] literature, which utilizes dynamic

state-space games game with network externalities in

Artem et al.

[46] which a state variable of each player

is influenced by her own decision

and the decisions of her

predecessors in the network

The paper used an evolutionary

Rocha ABD. et al. [36] game model to study the interplay

in a country facing a pollution trap

\begin{tabular}{lc}
\hline $\begin{array}{l}\text { Kucukmehmetoglu } \\
\text { et al. }\end{array} \quad[40]$ & $\begin{array}{c}\text { The cooperative game theory was } \\
\text { used as a water allocation } \\
\text { optimization model }\end{array}$ \\
\hline
\end{tabular}

This study developed a novel class

of cooperative dynamic games with

Petrosyan et al. [38] multiple durable controls of

different lag durations affecting

both the players' payoffs and the state dynamics

The paper proposed a dynamic game about the process of

Giovanni and Marta [47] formation and stability of international environmental agreements (IEAs)

The paper used dynamic optimisation to derive the

Luqman et al. minimum penalty cost on nations every single time 


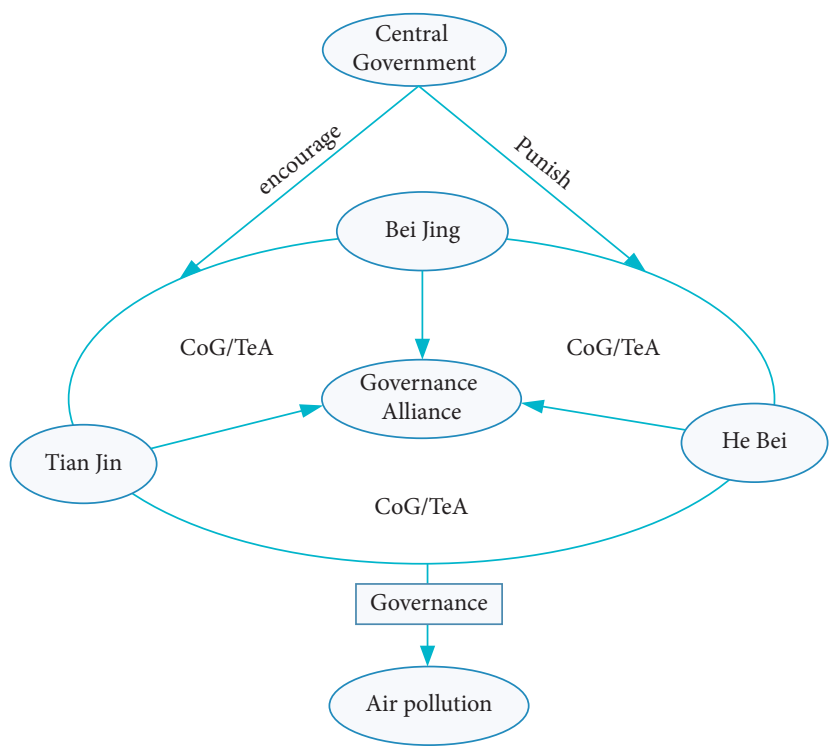

FIGURE 3: Decision-making framework on intergovernmental cooperative air pollution control.

\section{Assumptions and Construction of the Evolutionary Game Model}

4.1. Basic Assumptions. In this study, with the air pollution cities with boundary rationality in the Beijing-Tianjin-Hebei region as the main decision-making body, an analysis is conducted on the choice of air pollution control strategy without central government constraints and the choice of air pollution control strategy under central government constraints.

In a completely natural environment without other constraints, the urban agglomerations suffering from atmospheric pollution in the Beijing-Tianjin-Hebei region are considered a system and fall to two differentiated finite rational groups, i.e., urban group 1 and urban group 2 . This study considers that the two groups are composed of cities with slow learning speeds and repeatedly randomly draw a city pair from each of the two groups to form the game. The one drawn from city group 1 is termed as city 1 and from city group 2 is termed as city 2 . The respective city in city group 1 and city group 2 has two options: \{Cooperative control, Territorial autonomy\}.

For city group 1 , the proportion of cities complying with the cooperative control strategy is $x$ and the proportion of cities selecting the territorial autonomy strategy is $(1-x)$. For city group 2, the proportion of cities selecting the cooperative control strategy is $y$, and the proportion of cities complying with the territorial autonomy strategy is $(1-y)$, where, $0 \leq x \leq 1,0 \leq y \leq 1 ; x$ and $y$ are functions with respect to time $t$.

$C e_{i}(i=1,2)$ represents the total input of $i$ city for territorial autonomy air pollution as air pollution control will have a certain loss of economic growth for the city in the short term, the city can accept the loss of economic growth in the short term as $I_{i}(i=1,2)$, and air pollution will impose a certain loss on the city as $L_{i}(i=1,2)$.
$\operatorname{Re}_{i}(i=1,2)$ denotes the own benefit brought by city $i$ complying with the territorial autonomy strategy, and the public benefit brought by territorial autonomy to BeijingTianjin-Hebei region is $R i_{i}(i=1,2)$, and the public benefit to Beijing-Tianjin-Hebei region when both cities choose territorial autonomy is $R i$, then $R i>R i_{1}+R i_{2}$. It is assumed that when two cities in the region reach a cooperative control alliance, the cost of cooperation to be paid is $\mathrm{Cu}$, and the total benefit is Rs. Table 3 lists the corresponding parameters.

\subsection{Model Construction}

4.2.1. An Evolutionary Game Model for Cooperative Air Pollution Control without Constraints. Given the mentioned model assumptions, the game tree of city 1 and city 2 without any constraints is constructed as illustrated in Figure 4.

Based on the mentioned research hypotheses, this study calculates the expected revenues, E1, E2, of the cityl for CoG and TeA strategies, which are, respectively,

$$
\begin{aligned}
E_{1}= & y\left(\operatorname{Re}_{1}+R i+R s-C e_{1}-I_{1}-C u\right) \\
& +(1-y)\left(\operatorname{Re}_{1}+R i_{1}-C e_{1}-I_{1}-\alpha L_{2}\right) \\
= & \left(R i+R s-C u-R i_{1}+\alpha L_{2}\right) y \\
& +\left(\operatorname{Re}_{1}+R i_{1}-C e_{1}-I_{1}-\alpha L_{2}\right), \\
E_{2}= & y\left(\alpha L_{1}-L_{1}\right)+(1-y)\left(-L_{1}-\alpha L_{2}\right) \\
= & \left(\alpha L_{1}+\alpha L_{2}\right) y-L_{1}-\alpha L_{2} .
\end{aligned}
$$

The average revenue of cityl is

$$
\bar{E}=x E_{1}+(1-x) E_{2} \text {. }
$$

Then, we compute the expected revenues, $V_{1}$ and $V_{2}$, of city 2 for CoG and TeA strategies, respectively, 
TABLE 3: Main parameters and their meaning.

\begin{tabular}{|c|c|c|}
\hline Sign & Variable & Sources \\
\hline$C e_{i}$ & Total cost of air pollution for cities to conduct territorial autonomy & Luqman et al. [50] \\
\hline$I_{i}$ & Loss of economic growth in the short term that cities can accept due to air pollution control & $\begin{array}{l}\text { Mahan et al. and Artem et al. } \\
\qquad[44,46]\end{array}$ \\
\hline $\mathrm{L}_{\mathrm{i}}$ & The damage caused by atmospheric pollution to cities & Hongwei Wang et al. [37] \\
\hline $\operatorname{Re}_{i}$ & Self-benefits of cities complying with territorial autonomy strategies & $\begin{array}{l}\text { de Frutos et al. and Cabo et al. } \\
\qquad[31,34]\end{array}$ \\
\hline$R i_{i}$ & Public benefi & Jørgensen et al. [35] \\
\hline$R i$ & Public benefits to the region from territorially autonomous air pollution contr & Kucukmehmetoglu et al. [40] \\
\hline$C_{u}$ & Costs for two cities to reach a cooperative control alliance & Shan et al. [45] \\
\hline$R_{s}^{u}$ & Total benefit & al. [36] \\
\hline$P$ & The central governmer & Petrosyan et al. [38] \\
\hline$A$ & Central gove & Michele [39] \\
\hline & $\begin{array}{l}\text { The coefficient of intercity externalities, the negative externalities of air pollution, and the positive } \\
\text { externalities of air pollution control are all } \alpha(0<\alpha<1)\end{array}$ & Artem et al. [46] \\
\hline
\end{tabular}

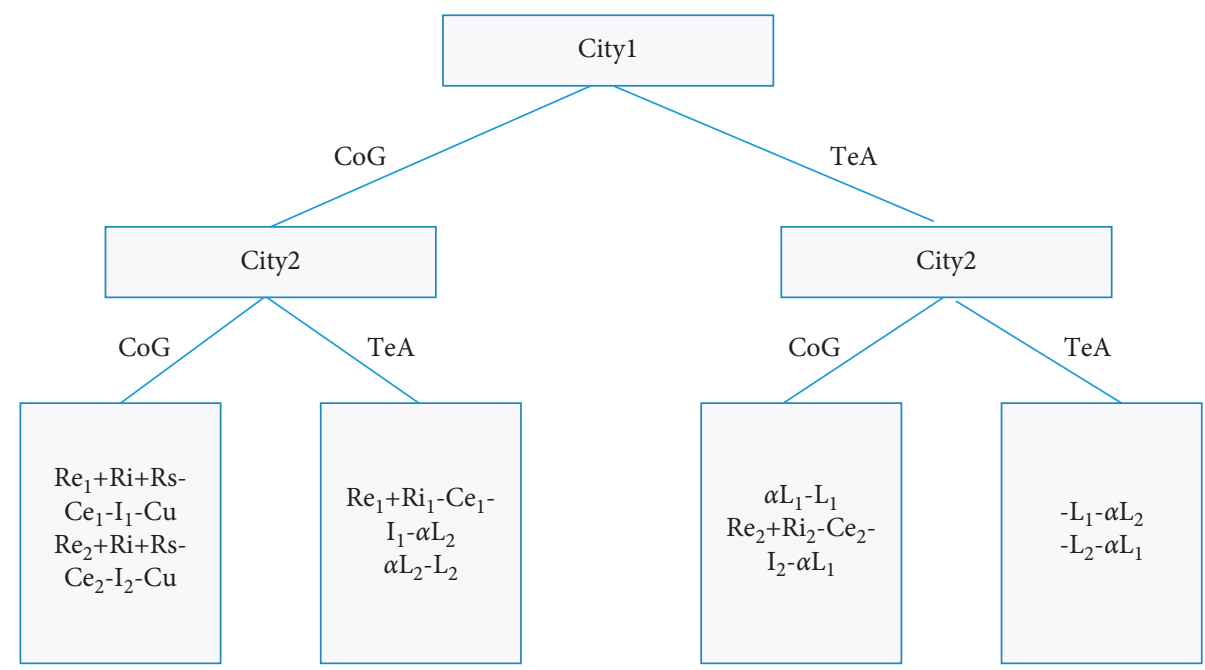

FIgURE 4: The game tree of city 1 and city 2 without constraints. Note: CoG represents the strategy "cooperative control" and TeA represents "territorial autonomy".

$$
\begin{aligned}
V_{1}= & x\left(\mathrm{Re}_{2}+R i+R s-C e_{2}-I_{2}-C u\right) \\
& +(1-x)\left(\mathrm{Re}_{2}+R i_{2}-C e_{2}-I_{2}-\alpha L_{1}\right) \\
= & \left(R i+R s-C u-R i_{2}+\alpha L_{1}\right) x+\mathrm{Re}_{2}+R i_{2}-C e_{2}-I_{2}-\alpha L_{1},
\end{aligned}
$$

$$
\begin{aligned}
V_{2} & =x\left(\alpha L_{2}-L_{2}\right)+(1-x)\left(-L_{2}-\alpha L_{1}\right) \\
& =\left(\alpha L_{2}+\alpha L_{1}\right) x-\alpha L_{1}-L_{2} .
\end{aligned}
$$

The average revenue of city2 is

$$
\bar{V}=y V_{1}+(1-y) V_{2} \text {. }
$$

According to the replicated dynamic equation $F(x)=\mathrm{d} x / \mathrm{d} t$, the dynamic equations for the probability $x$ of cityl when complying with CoG strategy and for the probability $y$ of city 2 when selecting the CoG strategy are expressed as

$$
\begin{aligned}
F(x) & =\frac{\mathrm{d} x}{\mathrm{~d} t}=x\left(E_{1}-\bar{E}\right)=x(1-x)\left(E_{1}-E_{2}\right) \\
& =x(1-x)\left[\left(R i+R s-C u-R i_{1}-\alpha L_{1}\right) y+\left(\mathrm{Re}_{1}+R i_{1}-C e_{1}-I_{1}+L_{1}\right)\right] \\
F(y) & =\frac{\mathrm{d} y}{\mathrm{~d} t}=y\left(V_{1}-\bar{V}\right)=y(1-y)\left(V_{1}-V_{2}\right)=y(1-y)\left[\left(R i+R s-C u-R i_{2}-\alpha L_{2}\right) x+\mathrm{Re}_{2}+R i_{2}-C e_{2}-I_{2}+L_{2}\right] .
\end{aligned}
$$


4.2.2. An Evolutionary Game Model for Cooperative Air Pollution Control under Central Government Constraints. To encourage cities in the Beijing-Tianjin-Hebei region to proactively join the air pollution control and transform from single to cooperative control, the central government should adopt macroregulatory measures to incentivize cities within urban agglomerations to establish air pollution control alliances. This study argues that the central government is capable of boosting the air pollution control alliances within urban agglomerations via reward and punishment mechanisms. The game tree of intergovernmental cooperation in air pollution control under central government constraints is illustrated in Figure 5.

Based on the above research hypotheses, the average expected returns of the mixed strategies of city 1 and city 2 are

$$
\begin{aligned}
\bar{E} & =x E_{1}+(1-x) E_{2} \\
& =x\left[\left(R i+R s-C u+A-R i_{1}+\alpha L_{2}\right) y+\left(\operatorname{Re}_{1}+R i_{1}-C e_{1}-I_{1}-\alpha L_{2}\right)\right]+(1-x)\left[\left(\alpha L_{1}+\alpha L_{2}\right) y-\left(L_{1}+\alpha L_{2}+P\right)\right], \\
\bar{V} & =y V_{1}+(1-y) V_{2} \\
& =y\left[\left(R i+R s-C u+A-R i_{2}+\alpha L_{1}\right) x+\left(\operatorname{Re}_{2}+R i_{2}-C e_{2}-I_{2}-\alpha L_{1}\right)\right]+(1-y)\left[\left(\alpha L_{2}+\alpha L_{1}\right) x-\left(L_{2}+\alpha L_{1}+P\right)\right] .
\end{aligned}
$$

The replication dynamic equations of city 1 and city 2 are

$$
\begin{aligned}
& F(x)=\frac{\mathrm{d} x}{\mathrm{~d} t}=x\left(E_{1}-\bar{E}\right)=x(1-x)\left(E_{1}-E_{2}\right)=x(1-x)\left[\left(R i+R s+A-C u-R i_{1}-\alpha L_{1}\right) y+\left(\operatorname{Re}_{1}+R i_{1}-C e_{1}-I_{1}+L_{1}+P\right)\right] \\
& F(y)=\frac{\mathrm{d} y}{\mathrm{~d} t}=y\left(V_{1}-\bar{V}\right)=y(1-y)\left(V_{1}-V_{2}\right)=y(1-y)\left[\left(R i+R s+A-C u-R i_{2}-\alpha L_{2}\right) x+\left(\operatorname{Re}_{2}+R i_{2}+L_{2}+P-C e_{2}-I_{2}\right)\right] .
\end{aligned}
$$

\section{Asymptotic Stability Analysis of Equilibrium Points}

5.1. Asymptotic Stability Analysis of the Two-Player Game without Any Constraints. City 1 and City 2 keep increasing their understanding of each other during the game, and their decision-making behaviour will be gradually regulated; therefore, this part analyses the evolutionary stability of the mutual effect of the two sides of the game. Respectively, if $F(x)=(\mathrm{d} x / \mathrm{d} t)=0$, get $x=0, x=1, y^{*}=\left(C e_{1}+I_{1}-L_{1}-\right.$
$\left.R i_{1}-\mathrm{Re}_{1}\right) /\left(R i-R i_{1}+R s-C u-\alpha L_{1}\right) \quad$ and $\quad$ if $F(y)=(\mathrm{d} y / \mathrm{d} t)=0$, get $y=0, y=1, x^{*}=\left(\mathrm{Ce}_{2}+I_{2}-L_{2}-\right.$ $\left.\mathrm{Re}_{2}-R i_{2}\right) /\left(R i+R s-C u-R i_{2}-\alpha L_{1}\right)$. This leads to four special equilibria and one general equilibrium for the evolutionary game model of the mentioned research problem: $O(0,0), A(1,0), B(1,1), C(0,1), D\left(x^{*}, y^{*}\right)$. By complying with the method proposed by Friedman, the Taylor expansion of (4) and (8), taking only one term, yields an approximate linear system of equations at the equilibrium point $\left(x^{*}, y^{*}\right)$,

$$
\left\{\begin{array}{l}
F(x)=\frac{\mathrm{d} x}{\mathrm{~d} t}=(1-2 x)\left[\left(R i+R s-C u-R i_{1}-\alpha L_{1}\right) y+\left(\mathrm{Re}_{1}+R i-C e_{1}-I_{1}+L_{1}\right)\right]\left(x-x^{*}\right) \\
+x(1-x)\left(R i+R s-C u-R i_{1}-\alpha L_{1}\right)\left(y-y^{*}\right), \\
F(y)=\frac{\mathrm{d} y}{\mathrm{~d} t}=y(1-y)\left(R i+R s-C u-R i_{2}-\alpha L_{2}\right)\left(x-x^{*}\right) \\
+(1-2 y)\left[\left(R i+R s-C u-R i_{2}-\alpha L_{2}\right) x+\left(\mathrm{Re}_{2}+R i_{2}-C e_{2}-I_{2}+L_{2}\right)\right]\left(y-y^{*}\right) .
\end{array}\right.
$$

Its Jacobi matrix is written as

$$
J=\left[\begin{array}{lc}
(1-2 x)\left[\left(R i+R s-C u-R i_{1}-\alpha L_{1}\right) y+\left(\mathrm{Re}_{1}+R i-C e_{1}-I_{1}+L_{1}\right)\right] & x(1-x)\left(R i+R s-C u-R i_{1}-\alpha L_{1}\right) \\
y(1-y)\left(R i+R s-C u-R i_{2}-\alpha L_{2}\right)(1-2 y)\left[\left(R i+R s-C u-R i_{2}-\alpha L_{2}\right) x+\left(R e_{2}+R i_{2}-C e_{2}-I_{2}+L_{2}\right)\right.
\end{array}\right] .
$$




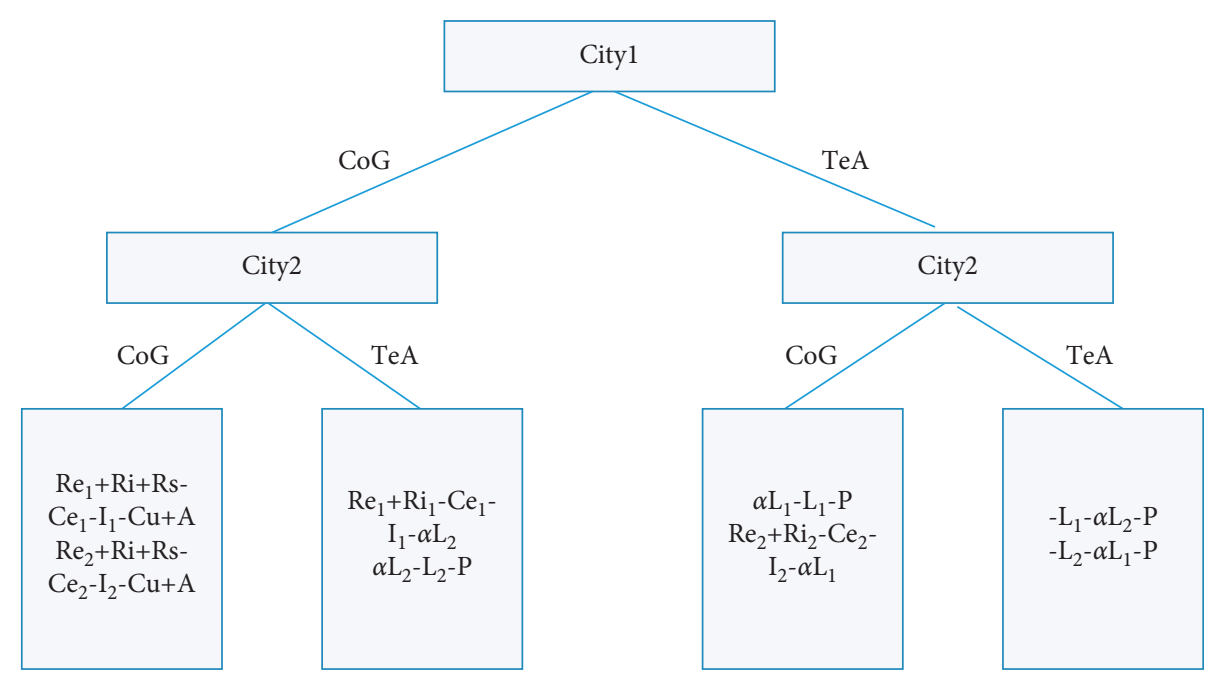

Figure 5: The game tree of city 1 and city 2 under central supervision. CoG represents the strategy "cooperative control" and TeA represents "territorial autonomy".

This leads to the characteristic root equation of the replicated dynamic equation as

$$
\left\{\begin{array}{l}
F^{\prime}(x)=(1-2 x)\left[\left(R i+R s-C u-R i_{1}-\alpha L_{1}\right) y+\left(\mathrm{Re}_{1}+R i-C e_{1}-I_{1}+L_{1}\right)\right] \\
F^{\prime}(y)=(1-2 y)\left[\left(R i+R s-C u-R i_{2}-\alpha L_{2}\right) x+\left(\mathrm{Re}_{2}+R i_{2}-C e_{2}-I_{2}+L_{2}\right)\right]
\end{array}\right.
$$

When $F^{\prime}(x)<0, F^{\prime}(y)<0$, the strategy adopted in city 1 and city 2 refers to an evolutionary stabilization strategy.

For city $1, \quad\left(R i+R s-C u-R i_{1}-\alpha L_{1}\right) y+\left(\operatorname{Re}_{1}+R i-\right.$ $\left.C e_{1}-I_{1}+L_{1}\right)=0$ is the cut-off for the steady state of city 1. If $\left(R i+R s-C u-R i_{1}-\alpha L_{1}\right) y+\left(\mathrm{Re}_{1}+R i-C e_{1}-I_{1}+\right.$ $\left.L_{1}\right)>0$, then $F^{\prime}(0)>0, F^{\prime}(1)<0$, which reveals that city 1 cooperation in the control of air pollution is a steady state, and that territorial autonomy air pollution is an unstable state. As opposed to the mentioned, if $F^{\prime}(0)<0$, $F^{\prime}(1)>0$, which demonstrates that city 1 territorial autonomous air pollution is a steady state and cooperative control is an unstable state. City 2 can be analysed in the same manner. It can be therefore concluded that among the five local equilibrium points, $O(0,0)$ and $B(1,1)$ are evolutionary stable strategies, which describe the strategies of city 1 and city 2 for air pollution control, either both territorially autonomous or cooperatively controlled (Figure 6).

Figure 6 illustrates the dynamic evolutionary process of the evolutionary game of cooperative air pollution control in urban agglomerations without constraints, which falls to two regions (i.e., $A B C D$ and $O A D C$ ) by saddle point $D$ in $O A B C$. The evolutionary game system converges to $B(1,1)$, when the set of strategy points falls in region $A B C D$, i.e., the cooperative control of city 1 and city 2 is the only evolutionary stable strategy for this game. In addition, when the strategy aggregation point falls in region $O A C D$, the evolutionary game system converges to $O(0,0)$. The final result is that city 1 and city 2 select territorial autonomy. Moreover, the evolutionary system is expected to evolve along the $B D$ path toward the $B(1,1)$ strategy, i.e., the larger the area of $A B C D$, the greater the chance of convergence of the strategy set points toward the $B(1,1)$ point. As revealed from $S_{A B C D}=1-\left(\left(x^{*}+y^{*}\right) / 2\right), x^{*}$ and $y^{*}$ are negatively correlated with $S_{A B C D}$ (Table 4 ). As a result, when two cities have more public benefits, their self-benefits, losses to cities from air pollution, and cobenefits from cooperative control, the larger the $S_{A B C D}$ will be, and the more they tend to cooperate in control. Accordingly, when two cities have lower total cost of air treatment in the two cities, short-term growth loss, and cost of cooperative treatment, the larger $S_{A B C D}$ will be and the more they are inclined to cooperate in control.

5.2. Asymptotic Stability Analysis of the Two-Player Game under Central Control. Likewise, when the central government controls, the evolutionary stability of the mutual effect of the two sides of the game is analysed: if $F(x)=0, x=0$, $x=1$, and $y^{*}=\left(C e_{1}+I_{1}-\mathrm{Re}_{1}-R i_{1}-L_{1}-P\right) /(R i+R s+$ $\left.A-C u-R i-\alpha L_{1}\right)$ if $F(y)=0, \quad y=0, \quad y=1$, and $x^{*}$ $=\left(C e_{2}+I_{2}-R_{2}-R i_{2}-L_{2}-P\right) /\left(R i+R s+A-C u-R i_{2}-\right.$ $\left.\alpha L_{2}\right)$. Similarly, $O(0,0), A(1,0), B(1,1), C(0,1), D\left(x^{*}, y^{*}\right)$ can be yielded. Based on the above analysis, it can be concluded that the two points $O(0,0)$ and $B(1,1)$ have local stability, which demonstrates that in the case of central government regulation, city 1 and city 2 are either territorial autonomy or cooperative control, as shown in Figure 7. 


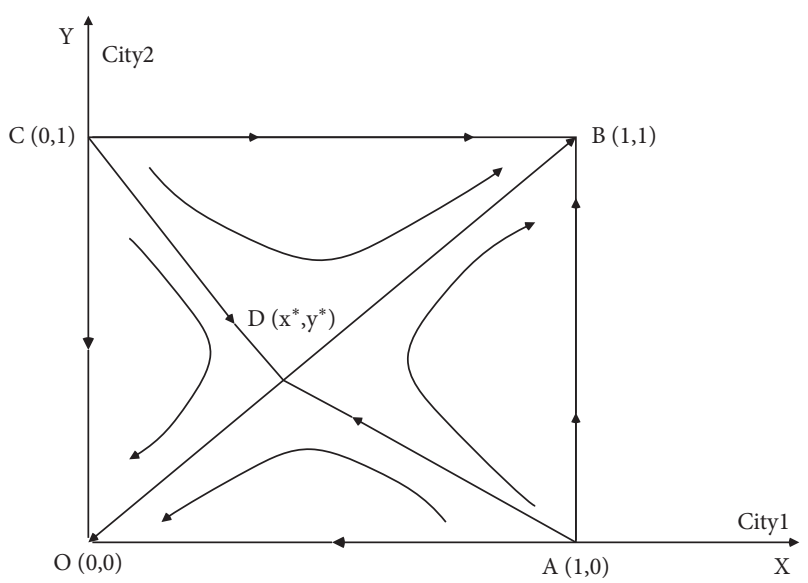

FIgURE 6: Phase diagram of the evolutionary game of cooperative air pollution control without constraints.

$O A B C$ is divided into two regions $A B C D$ and $O A D C$ by saddle point $D$. The evolutionary game system converges to $B(1,1)$,when the set of strategy points falls in region $A B C D$, i.e., the cooperative control of city 1 and city 2 is the only evolutionary stable strategy for this game. In addition, when the strategy aggregation point falls in region $O A C D$, the evolutionary game system converges to $O(0,0)$. The final result is that city 1 and city 2 choose territorial autonomy. In addition, we would like to see the evolutionary system evolve along the $B D$ path toward the $B(1,1)$ strategy, i.e., the larger the area of $A B C D$, the greater the chance of convergence of the strategy set points toward the $B(1,1)$ point. As shown in Table 5, we can see that, compared to the cooperative control game without any constraints, when the new parameters $P$ and $A$ of central government intervention and supervision come into play, they are both positively correlated with $S_{A B C D}$. This shows that the greater the central government's regulation and control, the higher the degree of rewards and punishments, and the greater the possibility that the two cities will reach a cooperative control alliance. Accordingly, the continuous stability of cooperative control is determined by the comprehensive income and the degree of central government regulation.

\section{Simulation Analysis of Cooperative Air Pollution Control Behaviour Model for the Beijing-Tianjin-Hebei Region}

From the above analysis, with or without constraints, the long-term evolution result of air pollution control behaviour of city 1 and city 2 may be either cooperation or autonomy, and the evolution equilibrium result is determined by the choice of specific variables and their changes.

To further examine the specific effects of variable changes on cities' air pollution control behaviour, it is necessary to assign values to parameters and quantitatively analyse the changes in the equilibrium of both sides of the game. In this study, Matlab is employed to simulate the trend diagram of the evolutionary changes of the model system. This study simulates the evolutionary state of cooperative air pollution control behaviour in the Beijing-Tianjin-Hebei region with and without central government constraints, and further analyses the factors of intergovernmental collaboration.

6.1. Variable Assignment. In this study, based on the on-site investigation of air pollution control in the Beijing-TianjinHebei region, combined with the city air quality reports released over the past few years and the statistical yearbook of air environment control, we set the probability of complying with the initial air pollution control behaviour of city 1 as $x=0$, the probability of selecting the initial air pollution control behaviour of city 2 as $y=0$, and we can set the basic parameter values as follows: $C e_{1}=5$ million yuan, $C e_{2}=4$ million yuan, $I_{1}=3$ million yuan, $I_{2}=2$ million yuan, $L_{1}=$ 8 million yuan, $L_{2}=7$ million yuan, $R e_{1}=6$ million yuan, $R e_{2}=5$ million yuan, $R i_{1}=3$ million yuan, $R i_{2}=4$ million yuan, $R i=5$ million yuan, $C u=6$ million yuan, $R s=4$ million yuan, $P=1$ million yuan, $A=2$ million yuan, $\alpha=0.55$.

As observed from the presented evolutionary game model, the impact of changes in the evolutionary equilibrium state is identified when the parameter values are adjusted by changes. The evolution of intergovernmental cooperative control without central government constraints is compared with the evolution of intergovernmental cooperative control with central government constraints to better explain the role of central government constraints in promoting intergovernmental cooperative control of air pollution in the Beijing-Tianjin-Hebei region and to analyse the key factors affecting the stability of intergovernmental cooperative control.

The variation in the parameter value interval complies with the evolutionary phase diagram that satisfies the equilibrium stability of city 1 in the impact equation (7) and the equilibrium stability of city 2 in the impact equation (8). If the phase diagram is satisfied, the smaller the magnitude of the parameter change is consistent with the realistic institutional environment. In this study, the adjustment variation of the initial value is set to be less than $20 \%$. The evolutionary changes of the equilibrium stable state of intergovernmental air pollution control with and without central constraints when the parameter values are changed are also observed in combination with the decision tree in Figures 4 and 5.

6.2. Game Evolution Simulation of Cooperative Control Behaviour among Cities in the Beijing-Tianjin-Hebei Region without Constraints. The evolutionary state of the game of cooperative control behaviour between cities in the BeijingTianjin-Hebei region without constraints in the initial assignment case is shown in Figure 8(a). As shown in the figure, from the analysis above, in the initial case, there are two states of the control behaviour strategies of city 1 and city 2 , either converging to 0 or converging to 1 , but this is not the result we want. With other values unchanged, adjusting the values of $R i_{1}$ to $3.6, R i_{2}$ to $6, \operatorname{Re}_{1}$ to $7.2, \operatorname{Re}_{2}$ to 6 , $L_{1}$ to $9, L_{2}$ to 8 , and $\mathrm{R}_{\mathrm{s}}$ to 4.8 , the figure is shown in Figure $8(\mathrm{~b})$, which demonstrates that the greater the public 
TABLE 4: Effect of parameter changes on evolutionary games without constraints.

\begin{tabular}{lcc}
\hline Parameter changes & Saddle point changes & Phase area change and evolutionary direction \\
\hline$R i_{1} \uparrow\left(R i_{2} \uparrow\right)$ & $y^{*} \downarrow\left(x^{*} \downarrow\right)$ & $S_{A B C D} \uparrow$ (Cooperative control, Cooperative control) \\
$\operatorname{Re}_{1} \uparrow\left(\operatorname{Re}_{2} \uparrow\right)$ & $y^{*} \downarrow\left(x^{*} \downarrow\right)$ & $S_{A B C D} \uparrow$ (Cooperative control, Cooperative control) \\
$L_{1} \uparrow\left(L_{2} \uparrow\right)$ & $y^{*} \downarrow\left(x^{*} \downarrow\right)$ & $S_{A B C D} \uparrow$ (Cooperative control, Cooperative control) \\
$C e_{1} \downarrow\left(C e_{2} \downarrow\right)$ & $y^{*} \downarrow\left(x^{*} \downarrow\right)$ & $S_{A B C D} \uparrow$ (Cooperative control, Cooperative control) \\
$I_{1} \downarrow\left(I_{2} \downarrow\right)$ & $y^{*} \downarrow\left(x^{*} \downarrow\right)$ & $S_{A B C D} \uparrow$ (Cooperative control, Cooperative control) \\
$R i \uparrow$ & $x^{*} \downarrow\left(y^{*} \downarrow\right)$ & $S_{A B C D} \uparrow$ (Cooperative control, Cooperative control) \\
$R s \uparrow$ & $x^{*} \downarrow\left(y^{*} \downarrow\right)$ & $S_{A B C D} \uparrow$ (Cooperative control, Cooperative control) \\
$C u \downarrow$ & $x^{*} \downarrow\left(y^{*} \downarrow\right)$ & $S_{A B C D} \uparrow$ (Cooperative control, Cooperative control) \\
\hline
\end{tabular}

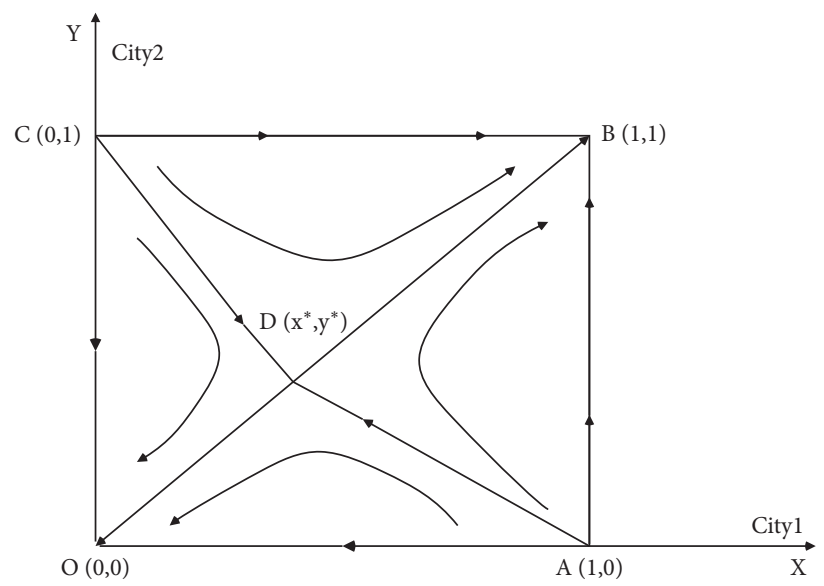

FIgURE 7: Phase diagram of the evolutionary game of cooperative air pollution control under central control.

TABLE 5: Effect of parameter changes on evolutionary games with constraints.

\begin{tabular}{lcc}
\hline Parameter changes & Saddle point changes & Phase area change and evolutionary direction \\
\hline$R i_{1} \uparrow\left(R i_{2} \uparrow\right)$ & $y^{*} \downarrow\left(x^{*} \downarrow\right)$ & $S_{A B C D} \uparrow$ (Cooperative control, Cooperative control) \\
$\operatorname{Re}_{1} \uparrow\left(\operatorname{Re}_{2} \uparrow\right)$ & $y^{*} \downarrow\left(x^{*} \downarrow\right)$ & $S_{A B C D} \uparrow$ (Cooperative control, Cooperative control) \\
$L_{1} \uparrow\left(L_{2} \uparrow\right)$ & $y^{*} \downarrow\left(x^{*} \downarrow\right)$ & $S_{A B C D} \uparrow$ (Cooperative control, Cooperative control) \\
$C e_{1} \downarrow\left(C e_{2} \downarrow\right)$ & $y^{*} \downarrow\left(x^{*} \downarrow\right)$ & $S_{A B C D} \uparrow$ (Cooperative control, Cooperative control) \\
$I_{1} \downarrow\left(I_{2} \downarrow\right)$ & $S_{A B C D} \uparrow$ (Cooperative control, Cooperative control) \\
$R i \uparrow$ & $y^{*} \downarrow\left(x^{*} \downarrow\right)$ & $S_{A B C D} \uparrow$ (Cooperative control, Cooperative control) \\
$R s \uparrow$ & $x^{*} \downarrow\left(y^{*} \downarrow\right)$ & $S_{A B C D} \uparrow$ (Cooperative control, Cooperative control) \\
$C u \downarrow$ & $x^{*} \downarrow\left(y^{*} \downarrow\right)$ & $S_{A B C D} \uparrow$ (Cooperative control, Cooperative control) \\
$P \uparrow$ & $x^{*} \downarrow\left(y^{*} \downarrow\right)$ & $S_{A B C D} \uparrow$ (Cooperative control, Cooperative control) \\
$A \uparrow$ & $x^{*} \downarrow\left(y^{*} \downarrow\right)$ & $S_{A B C D} \uparrow$ (Cooperative control, Cooperative control) \\
\hline
\end{tabular}

benefits of the two cities, their own benefits, the losses caused by air pollution to the cities, and the cobenefits of cooperative control, the more the behaviour of the two cities tend to cooperate in control. When adjusting the value of $C e_{1}$ to 4 , $\mathrm{Ce}_{2}$ to $3, I_{1}$ to $2, I_{2}$ to 1.5 , and $\mathrm{Cu}$ to 5 , the figure is shown in Figure $8(\mathrm{c})$, which indicates that the more the two cities' behaviour tends to cooperate in control when the total amount of air pollution control, the short-term growth loss and the cost of cooperation in air pollution control are lower for the two cities.

6.3. Simulation of Game Evolution of Cooperative Control Behaviour among Cities in the Beijing-Tianjin-Hebei Region with Constraints. To visualize the effect of central government constraints on the cooperative control behaviour between cities, the evolutionary state of cooperative air pollution control behaviour choice between two cities with constant initial values is shown in Figure 9(a). With the other values unchanged, adjusting the value of $A$ to 3 and the value of $P$ to 2 , we can obtain the evolutionary state of cooperative air pollution control behaviour of the two cities as shown in Figure 9(b). From Figure 9, it can be seen that after the introduction of the central government reward and punishment mechanism, the evolutionary equilibrium steady state of cooperative air pollution control in the two cities converges to 1 , and when the reward and punishment are increased, the speed of convergence is faster, i.e., the willingness to cooperate in control increases.

However, when the cost of control in the two cities increases, the central constraint seems to be difficult to 


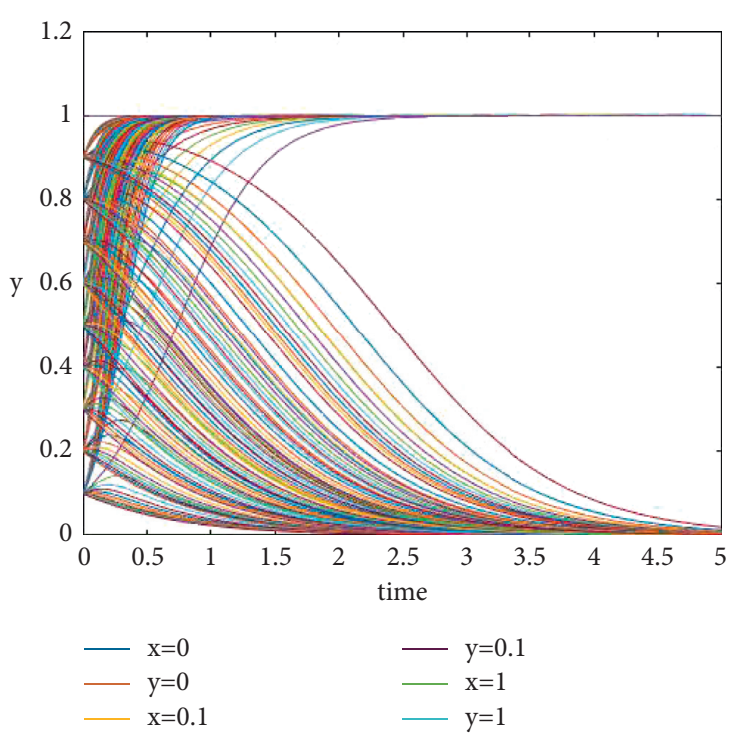

(a)

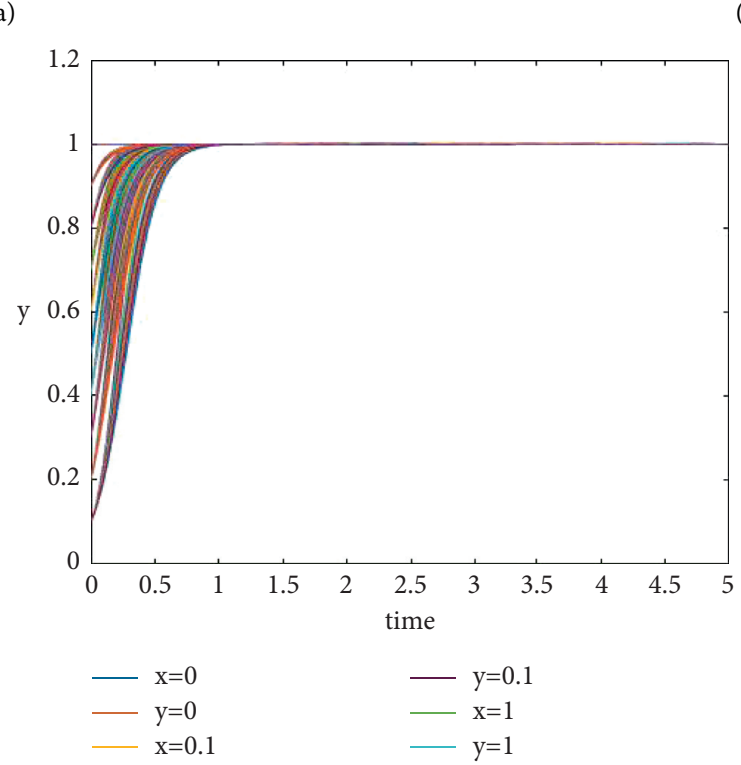

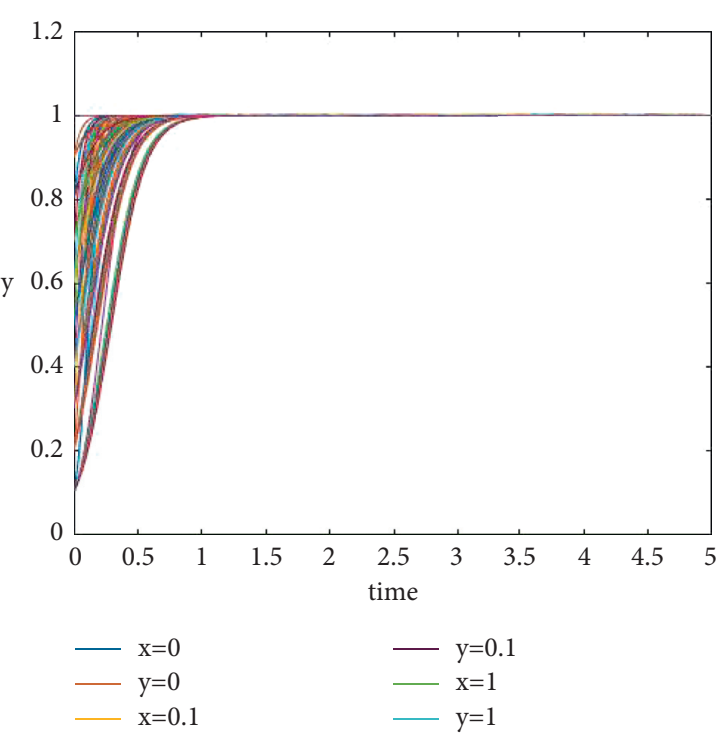

(b)

(c)

FIGURE 8: Evolution of the state of choice of air pollution control behaviour in the Beijing-Tianjin-Hebei region without constraints.

achieve. It can be seen from Figure 10(a) that the control behaviour decisions of the two cities have fallen into turbulence, the central government's reward and punishment measures have reduced the binding force on the cities, and the cities are more willing to take the risk of "free riders". They refused to take the initiative to form a control alliance. For this reason, what should we do at this time? Perhaps we have overlooked the comprehensive benefits of atmospheric control for cities. When we appropriately increase the benefits, the situation has changed again. As shown in Figure 10(b), the decision-making behaviour of players has stabilized again. Thus, the central government's incentives and punishments have increased the determination of the two cities to form an atmosphere control alliance. As indicated from Figure 10(c), the constraints of the central government have made the establishment of regional air control alliances more stable, and intercity cooperation has accessed into a long-term, sustainable, and virtuous circle.

As indicated from the figure, only under the dual role of comprehensive benefits and central government regulation, cities in the Beijing-Tianjin-Hebei region are more willing to reach cooperative air pollution control, while the long-term effective achievement of sustainable cooperative control is determined by the comprehensive benefits and the degree of central government regulation. 


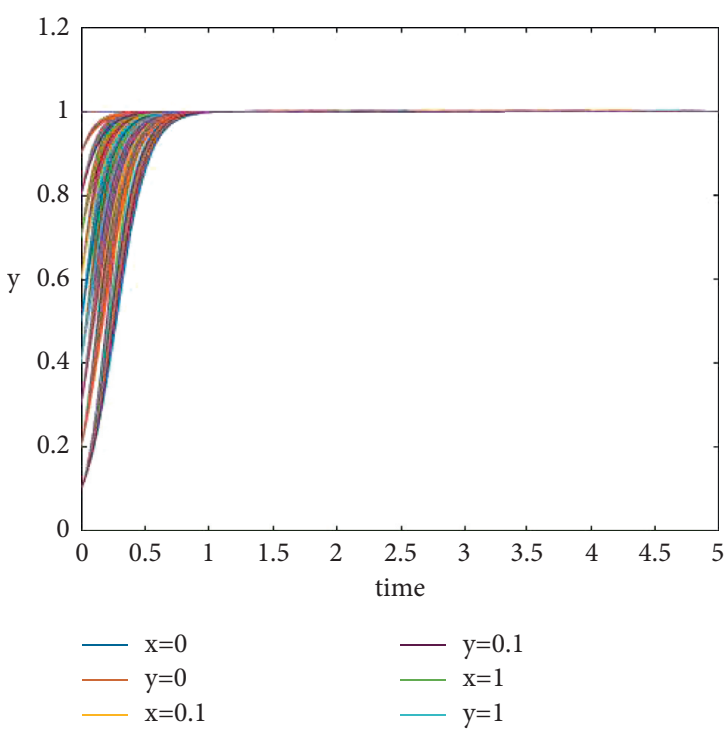

(a)

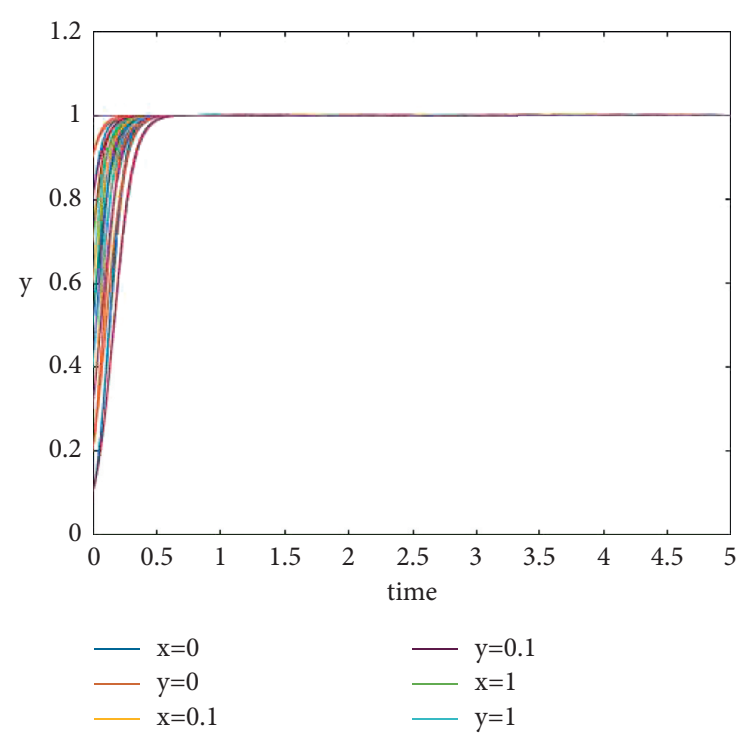

(b)

FIgURE 9: Evolution of the state of choice of air pollution control behaviour in the Beijing-Tianjin-Hebei region with constraints.

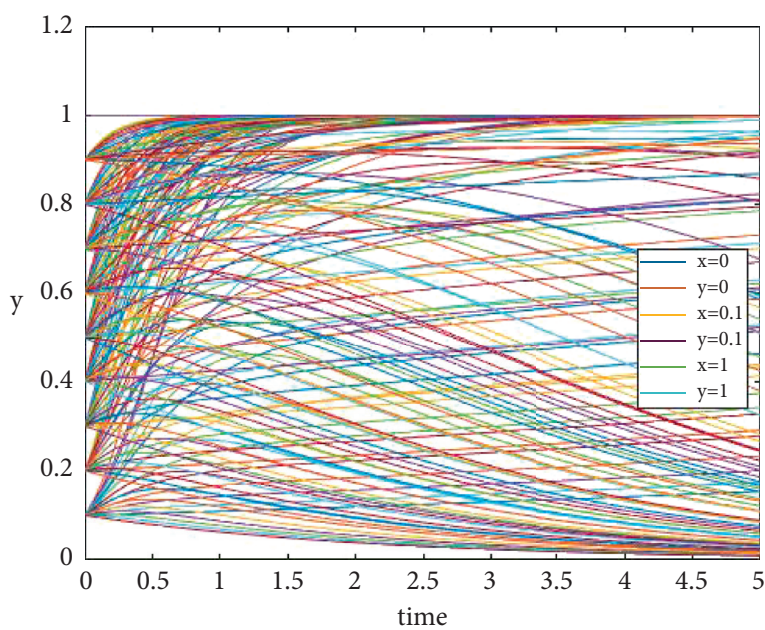

(a)

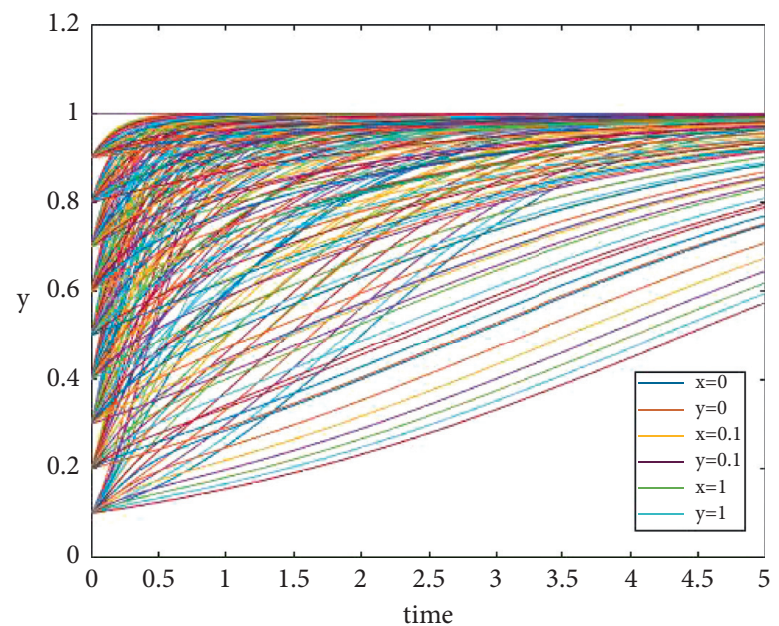

(b)

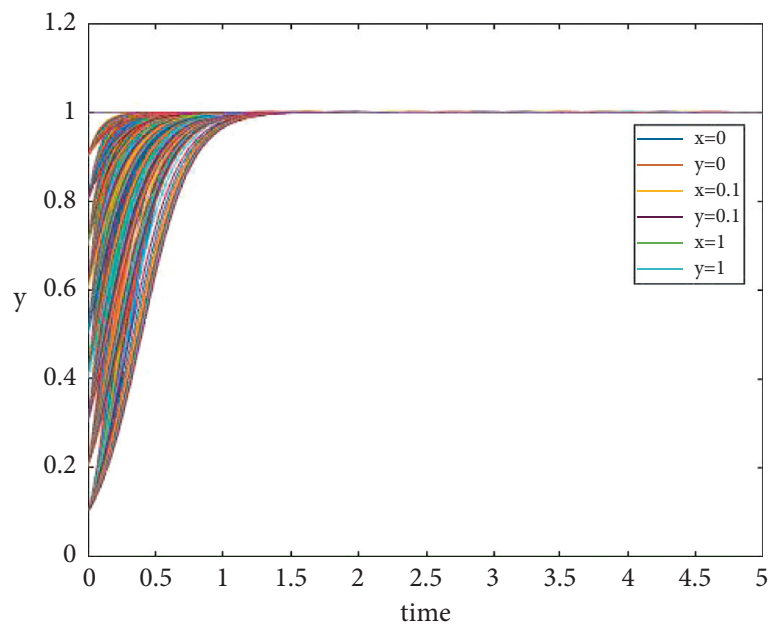

(c)

FIGURE 10: The stability of the air pollution control alliance restricted by the central government in the region under different conditions. 


\section{Conclusions}

This study discusses the dynamic evolution of the game of finite rational governments in the Beijing-Tianjin-Hebei region in cooperative air pollution control with and without central government constraints. First, based on the current dilemma of cooperative air pollution control in the BeijingTianjin-Hebei region and the inter-regional variability, this study constructs an evolutionary game model among cities in the Beijing-Tianjin-Hebei region and then analyses the asymptotic stability in the game process. Second, through the on-site investigation of the implementation of air pollution control in the Beijing-Tianjin-Hebei region, combined with the relevant contents of the statistical yearbook of the three provinces in 2020, the initial values of the external variables of the evolutionary game model are determined. Subsequently, the Matlab software is employed to simulate the evolution of the game between the two cities. Last, the two-party game process with or without the central government constraints is analysed, and the effect of the central government's reward and punishment mechanism on the game equilibrium is studied. The main conclusions are given below.

In the two-sided evolutionary game without the participation of the central government, the evolutionary stability strategy either tends to be 0 or 1 , which reveals that not all governments are willing to engage in cooperative control. The above results comply with the reality that there is an imbalance between the cost inputs and benefits of synergy in the Beijing-Tianjin-Hebei region, and the direct result of this imbalance is that the Hebei Province is "not active, not positive, and reluctant" to engage in the synergy [19]. As a result, "free-rider" situations inevitably occur, and the results cannot be changed by changing the initial policy.

When the central government controls the cooperative air pollution control in the Beijing-Tianjin-Hebei region, they adopt the reward and punishment strategy to change the evolutionary state of the game between them. After the introduction of the central government's reward and punishment mechanism, the evolutionary equilibrium steady state of cooperative air pollution control in the two cities converges to 1 , and the convergence rate is faster when increasing the reward and punishment, i.e., the willingness to cooperate in control increases. Thus, it can be seen that the long-term effective achievement of sustainable cooperative control is determined by the comprehensive benefits of each city in the Beijing-Tianjin-Hebei region and the degree of the central government regulation.

However, though the research in this study has certain practical significance, there are still limitations and defects. First, the research object of this study is the Beijing-TianjinHebei region, which has special characteristics. Given this, whether the research results are generalizable requires indepth studies. Second, there are more mechanisms that can be considered in the process of the evolutionary game (e.g., ecological compensation mechanism and air pollution propagation mechanism). Third, some parameters could be more specific, for instance, cost parameters could fall to control costs, technology costs, etc. Last, it is required to further explore the long-term effective achievement of sustainable cooperative control and find the influence that lead local governments to form a sustainable, mutually beneficial virtuous circle. Accordingly, the mentioned four aspects can be studied in depth in the subsequent research.

\section{Data Availability}

The data used to support the findings of this study are available from the corresponding author upon request.

\section{Conflicts of Interest}

The authors declare no conflicts of interest.

\section{Acknowledgments}

This research was supported by the Social Science Fund Project of Liaoning Province under Grant no. L20BZZ006.

\section{References}

[1] Center for Research on Energy and Clean Air (CREA), "Quantifying the economic costs of air pollution from fossil fuels," 2020, https://energyandcleanair.org/wp/wp-content/ uploads/2020/02/Cost-of-fossil-fuels-briefing.pdf.

[2] S. B. Brunnermeier and M. A. Cohen, "Determinants of environmental innovation in US manufacturing industries," Journal of Environmental Economics and Management, vol. 45, no. 2, pp. 278-293, 2003.

[3] I. Bailey and S. Rupp, "Geography and climate policy: a comparative assessment of new environmental policy instruments in the UK and Germany," Geoforum, vol. 36, no. 3, pp. 387-401, 2005.

[4] T. Omiya, "Japan's policies to address global environmental problems," Energy Conversion and Management, vol. 36, no. 6-9, pp. 381-486, 1995.

[5] A. Nurrohim and H. Sakugawa, "A fuel-based inventory of NOx and $\mathrm{SO} 2$ emissions from manufacturing industries in Hiroshima Prefecture, Japan," Applied Energy, vol. 78, no. 4, pp. 355-369, 2004.

[6] M. Karl-Göran, "International environmental problems," Oxford Review of Economic Policy, vol. 6, no. 1, pp. 80-108, 1990.

[7] S. Cai, Y. Wang, B. Zhao, S. Wang, X. Chang, and J. Hao, "The impact of the "air pollution prevention and control action plan" on PM2.5 concentrations in jing-jin-ji region during 2012-2020," The Science of the Total Environment, vol. 580, pp. 197-209, 2017.

[8] K. Emerson, T. Nabatchi, and S. Balogh, "An integrative framework for collaborative governance," Journal of Public Administration Research and Theory, vol. 22, no. 1, pp. 1-29, 2011.

[9] H. Zhao, K. Chen, Z. Liu et al., "“'Coordinated control of PM2.5 and O3 is urgently needed in China after implementation of the "Air pollution prevention and control action plan"” Chemosphere, vol. 270, Article ID 129441, 2021.

[10] M. Xu, Z. Qin, and S. Zhang, "Integrated assessment of cleaning air policy in China: a case study for Beijing-TianjinHebei region," Journal of Cleaner Production, vol. 296, Article ID 6085322, 2021. 
[11] D. Zhang, J. Liu, and B. Li, "Tackling air pollution in Chinawhat do we learn from the great smog of 1950s in london," Sustainability, vol. 6, no. 8, Article ID 061102, 2014.

[12] J. Li, “"Pollution emission trading: a possible solution to China's enforcement obstacles in fighting against air pollution?" UCLA Journal of Environmental Law and Policy, vol. 34, no. 1, pp. 56-98, 2016.

[13] W. T. Gormley, "Intergovernmental conflict on environmental policy: the attitudinal connection," The Western Political Quarterly, vol. 40, no. 2, pp. 285-303, 1987.

[14] S. Zheng and K. Luo, "Air pollution abatement efficiency and selection of environmental policy tools: empirical evidence of 29 provinces or municipalities," China Soft Science, vol. 9, pp. 184-192, 2017.

[15] J. Xue, L. Zhao, L. Fan, and Y. Qian, "An interprovincial cooperative game model for air pollution control in China," Journal of the Air \& Waste Management Association, vol. 65, no. 7, pp. 818-827, 2015.

[16] L. Xiao, Y. Qiao, J. Zhu et al., “"The "APEC blue” endeavor: causal effects of air pollution regulation on air quality in China," Journal of Cleaner Production, vol. 168, no. 6, pp. 1381-1388, 2017.

[17] W. Xue, J. Wang, H. Niu et al., “Assessment of air quality improvement effect under the national total emission control program during the twelfth national five-year plan in China," Atmospheric Environment, vol. 68, no. 6, pp. 78-81, 2013.

[18] N. Gunningham, "The new collaborative environmental governance: the localization of regulation," Journal of Law and Society, vol. 36, no. 1, pp. 145-166, 2009.

[19] N. Wei and Q. Meng, "Mechanism and institutional logic of cross-regional collaborative governance of air pollution-based on the cooperative practice of jing-jin-ji region," China Soft Science, vol. 10, pp. 79-92, 2018.

[20] C. Ansell and A. Gash, "Collaborative governance in theory and practice," Journal of Public Administration Research and Theory, vol. 18, no. 4, pp. 543-571, 2008.

[21] M. John, C. C. Bryson Barbara, and M. M. Stone, "The design and implementation of cross-sector collaborations: propositions from the literature," Public Administration Review, vol. 66, no. s1, pp. 44-55, 2006.

[22] K. Andreas, "Democratizing regional environmental governance: public deliberation and participation in transboundary ecoregions," Global Environmental Politics, vol. 12, no. 3, pp. 79-99, 2012.

[23] S. Min, "Regional cooperation for control of transboundary air pollution in East Asia," Journal of Asian Economics, vol. 12, no. 1, pp. 137-153, 2001.

[24] Y. Yan, H. Xu, Y. Jiang et al., "A modeling study of PM2.5 transboundary transport during a winter severe haze episode in southern Yangtze River Delta, China," Atmospheric Research, vol. 248, Article ID 105159, 2021.

[25] S. Wang and J. Hao, "Air quality management in China: issues, challenges, and options," Journal of Environmental Sciences, vol. 24, no. 1, pp. 2-13, 2012.

[26] J. Zhang, Z. Ouyang, H. Miao, and X. Wang, "Ambient air quality trends and driving factor analysis in Beijing, 19832007," Journal of Environmental Sciences, vol. 23, no. 12, pp. 2019-2028, 2011.

[27] G. Gualtieri, A. Crisci, M. Tartaglia et al., “Analysis of 20-year air quality trends and relationship with emission data: the case of Florence (Italy)," Urban Climate, vol. 10, no. 3, pp. 530-549, 2014.

[28] H. Wang, S.-C. Tan, Y. Wang et al., "A multisource observation study of the severe prolonged regional haze episode over eastern China in January 2013," Atmospheric Environment, vol. 89, pp. 807-815, 2014.

[29] G. Hardin, "The tragedy of the commons," Science, vol. 162, no. 3859, pp. 1243-1248, 1968.

[30] H. Li, C. Wang, M. Shang, W. Ou, and X. Qin, "Cooperative decision in a closed-loop supply chain considering carbon emission reduction and low-carbon promotion," Environmental Progress \& Sustainable Energy, vol. 38, no. 1, pp. 143-153, 2018.

[31] J. de Frutos and G. Martín-Herrán, "Spatial effects and strategic behavior in a multiregional transboundary pollution dynamic game," Journal of Environmental Economics and Management, vol. 97, pp. 182-207, 2019.

[32] S. Jørgensen and G. Zaccour, "Incentive equilibrium strategies and welfare allocation in a dynamic game of pollution control," Automatica, vol. 37, no. 1, pp. 29-36, 2001.

[33] H. Li, C. Wang, L. Xu, and W. Yu, "Pricing, carbon emission reduction, collection decision, and coordination in a lowcarbon closed-loop supply chain," Journal of Renewable and Sustainable Energy, vol. 9, no. 6, Article ID 065907, 2017.

[34] F. Cabo, E. Escudero, and G. Martín-Herrán, “A time-consistent agreement in an interregional differential game on pollution and trade," International Game Theory Review, vol. 8, no. 3, pp. 369-393, 2006.

[35] S. Jørgensen, G. Martín-Herrán, and G. Zaccour, "Dynamic games in the economics and management of pollution," Environmental Modeling and Assessment, vol. 15, no. 6, pp. 433-467, 2010.

[36] A. B. D. Rocha and G. M. Salomão, "Environmental policy regulation and corporate compliance in evolutionary game models with well-mixed and structured populations," European Journal of Operational Research, vol. 279, no. 2, pp. 486-501, 2019.

[37] H. Wang, L. Cai, and W. Zeng, "Research on the evolutionary game of environmental pollution in system dynamics model," Journal of Experimental and Theoretical Artificial Intelligence, vol. 23, no. 1, pp. 39-50, 2011.

[38] L. A. Petrosyan and D. W. K. Yeung, "Cooperative dynamic games with durable controls: theory and application," $D y$ namic Games and Applications, vol. 10, no. 4, pp. 872-896, 2020.

[39] M. Michele, "Regional governance of global climate change: the north American commission for environmental cooperation," Global Environmental Politics, vol. 7, no. 2, pp. 11-27, 2007.

[40] M. Kucukmehmetoglu and J.-M. Guldmann, "International water resources allocation and conflicts: the case of the euphrates and tigris," Environment and Planning A: Economy and Space, vol. 36, no. 5, pp. 783-801, 2004.

[41] P. W. Kennedy, "Equilibrium pollution taxes in open economies with imperfect competition," Journal of Environmental Economics and Management, vol. 27, no. 1, pp. 49-63, 1994.

[42] Y. Suzuki and Y. Iwasa, "Conflict between groups of players in coupled socio-economic and ecological dynamics," Ecological Economics, vol. 68, no. 4, pp. 1106-1115, 2009.

[43] A. Yanase, "Global environment and dynamic games of environmental policy in an international duopoly," Journal of Economics, vol. 97, no. 2, pp. 121-140, 2009.

[44] R. C. Mahan, T. M. Horbulyk, and J. G. Rowse, "Market mechanisms and the efficient allocation of surface water resources in southern Alberta," Socio-Economic Planning Sciences, vol. 36, no. 1, pp. 25-49, 2002.

[45] S. Shan, X. Duan, Y. Zhang, T. T. Zhang, and H. Li, "Research on collaborative governance of smart government based on 
blockchain technology: an evolutionary approach," Discrete Dynamics in Nature and Society, vol. 2020, Article ID 129441, 23 pages, 2021.

[46] S. Artem, Q. Han, and S. Wang, "A model of river pollution as a dynamic game with network externalities," European Journal of Operational Research, vol. 290, no. 3, pp. 1136$1153,2021$.

[47] V. Giovanni and B. Marta, "An evolutionary game approach in international environmental agreements with $\mathrm{R} \& \mathrm{D}$ investments," Computational Economics, vol. 54, no. 3, pp. 1027-1042, 2019.

[48] B. James and D. Bernhardt, "A numerical analysis of the evolutionary stability of learning rules," Games and Economic Behavior, vol. 67, no. 2, pp. 376-388, 2009.

[49] J. Josephson, "A numerical analysis of the evolutionary stability of learning rules," Journal of Economic Dynamics and Control, vol. 32, no. 5, pp. 1569-1599, 2008.

[50] M. Luqman, S. Peng, S. Huang, A. Bibi, and N. Ahmad, "Cost allocation for the problem of pollution reduction: a dynamic cooperative game approach," Economic Research-Ekonomska Istraživanja, vol. 31, no. 1, pp. 1717-1736, 2019. 